\title{
Epidemiology of attempted suicides in Southern Sri Lanka
}

\author{
Chandrasiri PAA ${ }^{1}$, Lokubalasuriya $\mathbf{A}^{2}$, Hettiarachchi $\mathbf{R}^{3}$ \\ ${ }^{\prime}$ Management Development and Planning Unit, ${ }^{2}$ Family Health Bureau, ${ }^{3}$ Nutrition Coordination Division, \\ Ministry of Health, Sri Lanka.
}

Correspondence: Dr. Amila Chandrasiri

e-mail: amilachan@yahoo.com

https://orcid.org/0000-0002-3242-1489

\begin{abstract}
Introduction: Suicides are emerging as an important public health issue globally. Suicide rate in Sri Lanka is higher than the global figure and is around 20 per 100,000 population. Knowledge on characteristics of subjects who attempt suicide will help to strengthen prevention programs. The aim of this study was to describe characteristics of patients who admitted following attempted suicides.
\end{abstract}

Methods: A descriptive cross sectional study was performed using an interviewer administered questionnaire in General hospital Hambantota, which is a tertiary care institute in southern Sri Lanka.

Results: Total sample consisted of 105 subjects. Mean age was 25.5 (SD 11.93) and 56.2\% were females. Except 4 subjects the rest were Sinhala Buddhists. Majority had only secondary education (71.4\%), were not employed (55.2\%) and belong to nuclear families (79.0\%). Though majority admitted an access to help (65.7\%), had good relationship with parents $(73.3 \%)$ and socially connected, there were $15.3 \%$ with past history of suicidal attempts and $64.7 \%$ had exposed to suicidal acts in media. There were $6.7 \%$ with depression who were all females and 5.7\% with alcohol dependence who were all males. Though 56.1\% reported recent stressful life events, only $27.6 \%$ had mentioned about recent disputes in a relationship.

Conclusions: Identification of vulnerable groups is of utmost importance in planning public health strategies to prevent attempted suicides. Preventive strategies should be specifically focused on those groups. Utilization of available support, improving personal skills to cope with daily stressors and relationship disputes should be promoted.

Keywords: Public health, Sri Lanka, suicides

\section{Introduction}

Suicides are emerging as an important public health issue worldwide. Every year an estimated number of 900000 people die by committing suicide. This represents one death every 40 seconds (1). Worldwide incidence of completed suicides is 16 per 100,000 population and it ranks as the $13^{\text {th }}$ leading cause of deaths, globally, according to current World Health Organization (WHO) statistics (2). Ten to twenty times more people attempt suicides than above incidence (3). This adds an immense burden to health care systems worldwide.
Sri Lanka became top ranked in the world by suicide rates in 1995 (47 per 100,000). Although there is a steady and a gradual declining of suicide rates since then, the rate recorded in 2008 was 20.4 per 100,000 of population (4). In 2008,4120 people succumbed to suicides (3260 males and 860 females) according to the Department of Police data. Though we do not have accurate figures, it is assumed that nearly 40,000 people attempt suicides each year. Therefore it is a major socioeconomic problem (5) and is high enough to be considered as a top public health issue in the country. 
Taking immediate actions to reduce the morbidity and mortality due to suicidal behaviour has become a top priority in WHO agenda. WHO has made a call for a co-ordinated and intensified global action to address this problem. Therefore area specific data is of utmost importance in planning and implementing prevention programs. Evidence based guidance for public health policy making is the key to reduce the burden of suicides.

Attempts to understand and prevent the occurrence of suicidal acts require the assessment of epidemiology of the problem in a given setting (6). Knowledge on characteristics of subjects who attempt suicide in a particular area will help to strengthen prevention programs and yield a better outcome.

Therefore the aim of this study was to describe characteristics of patients who were admitted following deliberate self-harm to a tertiary care institute in southern Sri Lanka.

\section{Methods}

Study was conducted in General Hospital Hambantota, a tertiary care institute in the Southern part of the country which caters for a population of nearly one million. A descriptive cross sectional study was performed using an interviewer administered questionnaire as the data collection tool. The data was collected from May to September in the year of 2011 .

A person presented with a nonfatal act of self-harm undertaken with conscious self-destructive intent was taken as a case of suicide attempt (7). Ascertainment of attempted suicide was done according to the diagnosis made by the Medical Officer-Mental Health (MO-MH). In routine practice, every deliberate self-harm case is referred to $\mathrm{MO}-\mathrm{MH}$ who is a postgraduate qualified medical officer in psychiatry who serves under the supervision of a consultant psychiatrist. The interview was performed when the patient was referred for psychiatric assessment by the MO-MH, therefore it was assumed that all the patients selected were physically and mentally capable of providing information. Those who were psychologically or emotionally disturbed or not in a state to undergo the interview were excluded. Eligible subjects were informed about the study and the interview was performed after obtaining written informed consent from the patients. Special emphasis was given to privacy, autonomy, non-maleficence and expected benefits.

Permission from hospital authority was obtained and minimal disruption to the routine patient care was assured. Ethical clearance for the study was obtained from ethics review committee of the Faculty of Medicine, Colombo.

Questionnaire used in the study was a selfconstructed one. Selection of variables was done by triangulation of methods. Several text books in psychiatry were scrutinized to identify main aspects of epidemiology of attempted suicides $(3,8)$. Thorough literature survey was done by referring relevant research publications based on the topic. Google scholar and PubMed were explored in finding relevant publications. Finally expert opinion was obtained with the objective of adjusting these variables to local setting. It was pretested with 10 cases in a General Hospital of an adjacent district and further modifications were made.

The questionnaire included background information and items to asses each variable. They were arranged into a logical order to make the interview more comfortable and facilitate recalling events. Simple language was used. Vague and emotional words were avoided.

The questionnaire was originally developed in English and then translated into Sinhala and Tamil languages. Back translations were done to match with the original English version. Standard diagnostic criteria for research given in ICD 10 classification of mental and behavioural disorders by WHO were used for the assessment of depression and alcohol dependence.

Data were collected by the principal investigator and four research assistants who were former psycho-social workers served under a WHO guided program. To reduce observation bias the research assistants were trained by the principal investigator with special attention on maintaining uniformity. The principal investigator and research assistants were trained by a Consultant Psychiatrist on 
detecting the two psychiatric conditions assessed in the study using ICD 10 classification of mental and behavioural disorders by WHO.

Patients identified with any of the two psychiatric illnesses assessed were referred to psychiatric unit for appropriate management. Those who needed socio-economic support were referred for pre identified government officers, non-governmental organizations or community based rehabilitation program conducted by the government. Subjects who needed counseling were referred to counseling officers attached to Divisional Secretariat offices in respective areas.

Data analysis was done by SPSS software. Relevant descriptive statistics were calculated and comparisons were done to elicit statistically significant characteristics.

\section{Results}

The sample included 105 eligible subjects who agreed to participate.

\section{Basic demographic characteristics of the study sample}

Distribution of basic demographic characteristics of the study sample is shown in table 1 .

The mean age of study subjects was 25.5 (SD11.9) years and the age range was from 12 to 70 . Majority of them $(57.2 \%)$ belonged to $16-25$ age group. Females (56.2\%) exceeded males in number. Except four subjects the rest of the study population were Sinhala Buddhists. Fifty eight subjects (55.3\%) reported a monthly family income of Rs. 10,000/- to $30,000 /-$ while 46 subjects $(43.8 \%)$ admitted that they had below Rs. 10,000/- monthly family income. Majority of the sample had educated from grade 6 to $11(71.4 \%)$, not employed (55.2\%) and belonged to nuclear families $(79.0 \%)$. Study population consisted of nearly equal portions of married and unmarried subjects (50.5\% and $49.5 \%)$.

Surprisingly $65.7 \%$ of patients admitted that they have an access to help, which means the availability of trustworthy person to talk confidentially when a problem arose. Also the variables which measured social connectedness showed that the most of them were either a member of a community organization, a society or a club $(54.3 \%)$ and involved in team work e.g. sport activities (60.9\%). Larger proportion of subjects acknowledged (78.1\%) that they were not physically abused during childhood and had a good relationship with parent during childhood $(73.3 \%)$. When inquiring about exposure to suicidal acts in media, majority $(64.7 \%)$ revealed that they were exposed to suicidal acts in media (table 2).

There were 7 subjects $(6.7 \%)$ with depression and $6(5.7 \%)$ with alcohol dependence in the study sample. Nine patients $(8.6 \%)$ were reported to have chronic painful illnesses. Majority (56.1\%) had gone through a recent stressful life event. Among all participants, $46.1 \%$ and $27.6 \%$ had recent (within the last 6 months) dispute with spouse or a close relative respectively. Only $16.1 \%$ had a recent meeting with a doctor (within the previous month). Among the participants $15.3 \%$ reported a past history of suicidal attempt (table 3 ).

Association between basic demographic characteristics and having recent stressful life events was separately assessed and results are presented in table 4.

Among those who reported a recent stressful life event, $73.3 \%$ belonged to nuclear families rather than extended families and it showed a significant difference $(p=0.097)$ (level of significance was taken as $10 \%$ ). Being in a nuclear family was significantly related with exposing into stressful life events. All other variables didn't show significant association with having recent stressful life events.

After assessing the association between basic demographic characteristics and recent dispute in a close relationship, it showed the majority $(79.3 \%)$ of those who reported recent such an incident were below 25 years and it was a statistically significant difference $(\mathrm{p}=0.041)$. 
Table 1: Basic demographic characteristics

\begin{tabular}{|c|c|c|}
\hline \multirow{2}{*}{ Characteristic } & \multicolumn{2}{|c|}{ Subjects $(n=105)$} \\
\hline & Frequency & Percentage \\
\hline \multicolumn{3}{|l|}{ Age category (years) } \\
\hline 15 and below & 7 & $6.7 \%$ \\
\hline $16-25$ & 60 & $57.2 \%$ \\
\hline $26-35$ & 20 & $19.0 \%$ \\
\hline $36-45$ & 10 & $9.5 \%$ \\
\hline $46-55$ & 5 & $4.8 \%$ \\
\hline 65 and above & 3 & $2.9 \%$ \\
\hline \multicolumn{3}{|l|}{ Sex } \\
\hline Female & 58 & $55.2 \%$ \\
\hline Male & 47 & $44.8 \%$ \\
\hline \multicolumn{3}{|l|}{ Ethnicity } \\
\hline Sinhala & 102 & $97.1 \%$ \\
\hline Tamil & 1 & $0.9 \%$ \\
\hline Muslim & 2 & $2.0 \%$ \\
\hline \multicolumn{3}{|l|}{ Religion } \\
\hline Buddhist & 101 & $96.2 \%$ \\
\hline Islamic & 2 & $1.9 \%$ \\
\hline Catholic & 2 & $1.9 \%$ \\
\hline \multicolumn{3}{|l|}{ Family income (Rs.) } \\
\hline Below 10000 & 46 & $43.8 \%$ \\
\hline $10000-30000$ & 58 & $55.3 \%$ \\
\hline $30000-60000$ & 0 & $0 \%$ \\
\hline Above 60000 & 1 & $0.9 \%$ \\
\hline \multicolumn{3}{|l|}{ Level of education } \\
\hline No school education & 3 & $2.9 \%$ \\
\hline Up to grade 5 & 10 & $9.5 \%$ \\
\hline From grade 6 to 11 & 75 & $71.4 \%$ \\
\hline From grade 12 to 13 & 13 & $12.3 \%$ \\
\hline Higher education & 4 & $3.9 \%$ \\
\hline \multicolumn{3}{|l|}{ Marital status } \\
\hline Married & 53 & $50.5 \%$ \\
\hline Unmarried & 52 & $49.5 \%$ \\
\hline \multicolumn{3}{|l|}{ Employment status } \\
\hline Currently employed & 47 & $44.8 \%$ \\
\hline Unemployed & 58 & $55.2 \%$ \\
\hline \multicolumn{3}{|l|}{ Family type } \\
\hline Nuclear family & 83 & $79.0 \%$ \\
\hline Extended family & 22 & $21.0 \%$ \\
\hline
\end{tabular}


Table 2: Distribution of socio - cultural characteristics

\begin{tabular}{lcc}
\hline \multicolumn{1}{c}{ Characteristic } & \multicolumn{2}{c}{ Subjects $(\mathbf{n}=\mathbf{1 0 5})$} \\
\cline { 2 - 3 } & Frequency & Percentage \\
\hline Access to help & 36 & $34.3 \%$ \\
$\quad$ Not available & 69 & $65.7 \%$ \\
$\quad$ Available & & \\
Being a member of any community organization /society /club & 57 & $54.3 \%$ \\
$\quad$ Yes & 48 & $45.7 \%$ \\
$\quad$ No & & \\
Being involved into any team sport & 64 & $60.9 \%$ \\
$\quad$ Yes & 41 & $39.1 \%$ \\
$\quad$ No & & \\
History of physical abuse & 22 & $20.9 \%$ \\
$\quad$ Yes & 83 & $79.1 \%$ \\
$\quad$ No & & \\
Relationship with parents during the childhood & 28 & $26.7 \%$ \\
$\quad$ Not good & 77 & $73.3 \%$ \\
$\quad$ Good & & \\
Exposure to suicidal act in media & 37 & $35.3 \%$ \\
$\quad$ No & 68 & $64.7 \%$ \\
$\quad$ Yes & & \\
&
\end{tabular}

Table 3: Distribution of psychological and biological characteristics

\begin{tabular}{|c|c|c|}
\hline \multirow{2}{*}{ Characteristic } & \multicolumn{2}{|c|}{ Subjects $(n=105)$} \\
\hline & Frequency & Percentage \\
\hline \multicolumn{3}{|l|}{ Presence of Depression } \\
\hline Yes & 7 & $6.7 \%$ \\
\hline No & 98 & $93.3 \%$ \\
\hline \multicolumn{3}{|c|}{ Presence of Alcohol dependence } \\
\hline Yes & 6 & $5.7 \%$ \\
\hline No & 99 & $94.3 \%$ \\
\hline \multicolumn{3}{|c|}{ Presence of a Chronic painful illness } \\
\hline No & 96 & $91.4 \%$ \\
\hline Yes & 9 & $8.6 \%$ \\
\hline \multicolumn{3}{|c|}{ Having recent stressful life event } \\
\hline Yes & 59 & $56.1 \%$ \\
\hline No & 46 & $43.9 \%$ \\
\hline \multicolumn{3}{|l|}{ Recent dispute with spouse } \\
\hline Yes & 24 & $46.1 \%$ \\
\hline No & 28 & $53.9 \%$ \\
\hline \multicolumn{3}{|c|}{ Recent dispute in a close relationship } \\
\hline Yes & 29 & $27.6 \%$ \\
\hline No & 76 & $72.4 \%$ \\
\hline \multicolumn{3}{|l|}{ Recent meeting with a doctor } \\
\hline Yes & 17 & $16.1 \%$ \\
\hline No & 88 & $83.9 \%$ \\
\hline \multicolumn{3}{|c|}{ Family history of suicidal attempt } \\
\hline Yes & 42 & $40.0 \%$ \\
\hline No & 63 & $60.0 \%$ \\
\hline \multicolumn{3}{|l|}{ Past history of suicide attempt } \\
\hline Yes & 16 & $15.3 \%$ \\
\hline No & 89 & $84.7 \%$ \\
\hline
\end{tabular}


Table 4: Association between basic demographic characteristics and having recent stressful life events

\begin{tabular}{|c|c|c|c|c|c|}
\hline \multirow[t]{2}{*}{ Variable } & \multicolumn{2}{|c|}{$\begin{array}{c}\text { Having recent stressful } \\
\text { life events } \\
\end{array}$} & \multicolumn{2}{|c|}{$\begin{array}{l}\text { Not having recent } \\
\text { stressful life events }\end{array}$} & \multirow[t]{2}{*}{ Significance* } \\
\hline & Frequency & Percentage & Frequency & Percentage & \\
\hline \multicolumn{6}{|l|}{$\operatorname{Age}^{* *}$} \\
\hline Below 25 years $(n=67)$ & 37 & $6.7 \%$ & 30 & $0.9 \%$ & $\mathrm{x}^{2}=0.278$ \\
\hline Above 26 years $(n=38)$ & 23 & $93.3 \%$ & 15 & $99.1 \%$ & $\mathrm{p}=0.59$ \\
\hline \multicolumn{6}{|l|}{ Gender } \\
\hline Male $(n=47)$ & 30 & $50.0 \%$ & 17 & $37.8 \%$ & $x^{2}=1.55$ \\
\hline Female $(n=58)$ & 30 & $50.0 \%$ & 28 & $62.2 \%$ & $\mathrm{p}=0.21$ \\
\hline \multicolumn{6}{|l|}{ Family income $^{\#}$} \\
\hline Below Rs. 10,000 (n= 46) & 27 & $45.0 \%$ & 19 & $42.2 \%$ & $\mathrm{x}^{2}=0.081$ \\
\hline Above Rs. 10,001 (n=59) & 33 & $55.0 \%$ & 26 & $57.8 \%$ & $\mathrm{p}=0.78$ \\
\hline \multicolumn{6}{|l|}{ Education status ${ }^{\# \#}$} \\
\hline Grade 11 and below $(\mathrm{n}=88)$ & 51 & $85.0 \%$ & 37 & $82.2 \%$ & $\mathrm{x}^{2}=0.146$ \\
\hline Grade 12 and above $(n=17)$ & 9 & $15.0 \%$ & 8 & $178 \%$ & $\mathrm{p}=0.70$ \\
\hline \multicolumn{6}{|l|}{ Family type } \\
\hline Nuclear family (n=83) & 44 & $73.3 \%$ & 39 & $86.7 \%$ & $x^{2}=2.760$ \\
\hline Extended family $(n=22)$ & 16 & $26.7 \%$ & 6 & $13.3 \%$ & $\mathrm{p}=0.09$ \\
\hline
\end{tabular}

* Significance was tested by calculating chi square value $\left(\mathrm{x}^{2}\right)$ and $\mathrm{p}$ value

** For analysis subjects were divided into 2 age categories

\# For analysis subjects were divided into 2 income categories

\#\# For analysis subjects were divided into 2 categories of education status

Table 5: Association between basic demographic characteristics and recent dispute in a close relationship

\begin{tabular}{|c|c|c|c|c|c|}
\hline \multirow[t]{2}{*}{ Variable } & \multicolumn{2}{|c|}{$\begin{array}{l}\text { Having dispute in a close } \\
\text { relationship }\end{array}$} & \multicolumn{2}{|c|}{$\begin{array}{c}\text { Not having dispute in a } \\
\text { close relationship }\end{array}$} & \multirow[t]{2}{*}{ Significance } \\
\hline & Frequency & Percentage & Frequency & Percentage & \\
\hline \multicolumn{6}{|l|}{$\operatorname{Age}^{* *}$} \\
\hline Below 25 years $(n=67)$ & 23 & $79.3 \%$ & 44 & $57.9 \%$ & $x^{2}=4.169$ \\
\hline Above 26 years $(n=38)$ & 6 & $20.7 \%$ & 32 & $42.1 \%$ & $p=0.041$ \\
\hline \multicolumn{6}{|l|}{ Gender } \\
\hline Male $(\mathrm{n}=47)$ & 15 & $51.7 \%$ & 32 & $42.1 \%$ & $x^{2}=0.785$ \\
\hline Female $(\mathrm{n}=58)$ & 14 & $48.3 \%$ & 44 & $57.9 \%$ & $\mathrm{p}=0.375$ \\
\hline \multicolumn{6}{|l|}{ Family income $^{\#}$} \\
\hline Below $10000(n=46)$ & 10 & $34.4 \%$ & 36 & $47.4 \%$ & $x^{2}=1.416$ \\
\hline Above 10001(n=59) & 19 & $65.6 \%$ & 40 & $52.6 \%$ & $\mathrm{p}=0.234$ \\
\hline \multicolumn{6}{|l|}{ Education status } \\
\hline Grade II and below $(\mathrm{n}=88)$ & 26 & $89.7 \%$ & 62 & $81.6 \%$ & $x^{2}=1.009$ \\
\hline Grade 12 and above $(n=17)$ & 3 & $10.3 \%$ & 14 & $18.4 \%$ & $\mathrm{p}=0.315$ \\
\hline \multicolumn{6}{|l|}{ Family type } \\
\hline Nuclear family $(\mathrm{n}=83)$ & 21 & $72.4 \%$ & 62 & $81.6 \%$ & $\mathrm{x}^{2}=1.065$ \\
\hline Extended Family $(\mathrm{n}=22)$ & 8 & $27.6 \%$ & 14 & $18.4 \%$ & $\mathrm{p}=0.302$ \\
\hline
\end{tabular}

* Significance was tested by calculating chi square value $\left(\mathrm{x}^{2}\right)$ and $\mathrm{p}$ value

** For analysis subjects were divided into 2 age categories

\# For analysis subjects were divided into 2 income categories

\#\# For analysis subjects were divided into 2 categories of education status 


\section{Discussion}

This study was intended to explore the characteristics of people who attempted suicides in Southern Sri Lanka. Basic demographic features and important socio-cultural, psychological and biological characteristics were described separately.

Female dominance in attempted suicides which is known in medical literature (3) was reaffirmed. But bimodal association between age and incidence of attempted suicides which was also shown in local studies (9) was not noted. The ascertainment of outcome totally depended on patient's declaration of the intent. Those who committed the act without intention of killing him/herself may come out with a different reasoning later. Over representation of younger group in the sample can be due to ascertainment bias.

When looked at ethnic and religious composition of Hambantota it is noted that $11 \%$ of other ethnic and $10 \%$ of other religious population were in the district other than Sinhala Buddhists (10). But incidence of attempted suicides among other ethnic and religious groups were very low. Most of the Muslim community which is the second largest ethnic group in Hambantota live in urban areas and involved in business. So they tend to seek medical care from private sector.

Though being married is noted as a protective factor $(11,12)$ the proportion of married subjects among the sample was $50.5 \%$. Being in a nuclear family increased the likelihood of attempted suicides. But the majority had access to help and socially connected though they are protective factors against suicidal behaviour. Degree of utilization of available support and social networks should be further assessed. Though majority of the sample reported exposure to suicidal acts in media we need to consider that suicide reporting in media is abundant than ever it became more generalized.

Depression and alcohol dependence are two common psychiatric conditions associated with suicidal behavior (3). Reported incidences depend on the accuracy of diagnosis of those conditions by research assistants. But all the subjects with depression in the study sample were females and all with alcohol dependence were males. In Sri Lanka alcohol consumption by women is not socially accepted and a very little number of females take alcohol. Also it is confined to urban areas. Prevalence studies on depression conducted in Sri Lanka show female predominance. But this finding is interesting and it warrants more attentions should be paid on detection and treatment of depression among young females. Both stressful life events and disputes in close relationships are known as precipitating factors for suicidal attempts. Though $56.1 \%$ mentioned about recent stressful life events a lesser proportion reported recent disputes with their spouses and in close relationships.

A significant difference was noted in family status of those who reported recent stressful life events. Living in an extended family was noted as a protective factor for exposing into stressful life events, which is a known precipitating factor for suicidal acts. As the family consists of grand parents and siblings opportunity to cope with daily challenges of life is enhanced as more support is available within own family. Therefore strengthening family ties should be promoted.

A significant age difference was noted among those who reported recent disputes in close relationships. Younger patients were subjected to adverse relationship issues more than older subjects. Lack of life skills to maintain a healthy relationship is the apparent reason.

A hospital based sample was taken for this study and hence can lead to selection bias. A community based sample would have given the whole picture though cost and effort arise as barriers. Some factors had shown a contradicting relationship with known literature. An analytical approach using a control group would have elaborated the true association of variables with attempted suicides. Further studies are warranted to establish whether the observed differences are true or not.

Identification of vulnerable groups is of utmost importance in planning public health strategies to prevent attempted suicides. Being below 25 years (precisely 16 - 25) of age belonging to nuclear families and having had recent stressful life events were noted as vulnerable for attempted suicides. Preventive strategies should be specifically focused on those groups. Utilization of available support, improving personal skills to cope with daily stressors and relationship disputes should be promoted. 


\section{Acknowledgements}

Director, District General Hospital, Hambantota and Dr. Manoj Panamulla, the Consultant Psychiatrist, Teaching Hospital, Hambantota for their continuous support.

\section{References}

1. World Health Organization. How can suicide be prevented World Health Organization; 2010 [updated $07^{\text {th }}$ April 2011; cited $201107^{\text {th }}$ April]. Available from: http://www.who.int/ features/qa/24/en/index.html

2. World Health Organization. World suicide rates: World Health Organization; 2010 [updated 06 ${ }^{\text {th }}$ August 2011; cited $201106^{\text {th }}$ August]. Available from: http//www.int/ mentalhealth/topic_suicide/suicide_rates.html

3. Lonnquist JK. Epidemiology and causes of suicide. Oxford: Oxford University Press; 2009.

4. Sri Lanka Sumithrayo. Statistics and Data of Suicides: Sri Lanka Sumithrayo; 2010 [updated $05^{\text {th }}$ September 2011; cited $201105^{\text {th }}$ September]. Available from: http://srilankasumithrayo.org/statistics-a-data.

5. Fernando RHM, Priyangika WD, Range S, Karunaratne S. Study of suicides reported to the Coroner in Colombo, Sri Lanka. Medicine, Science and the Law. 2010; 50(1): 25-8.
6. World Health Organization (WHO). Prevention of suicide: guidelines for the formulation and implementation of national strategies. Geneva: 1996.

7. World Health organization. Guidelines for the primary prevention of mental, neurological and psychological disorders. Geneva: WHO; 1993.

8. Sadock B, Sadock V, editors. Kaplan and Sadock's Synopsis of Psychiatry: Behavioural Sciences/Clinical Psychiatry. 10ed: Lippincott, Williams and Wilkins 2007.

9. De Silva D. Suicide Prevention-A Sri Lankan Perspective. Mental health care issues and challenges. 2002: 112-6.

10. Regional Director of Health Services Hambantota. Annual Mental Health Report 2010. 2010: 4.

11. Kposowa AJ. Marital status and suicide in the National Longitudinal Mortality Study. Journal of Epidemiology and Community Health. 2000; 54: 254-61.

12. Luoma JB, Pearson JL. Suicide and Marital Status in the United States, 1991-1996: Is Widowhood a Risk Factor? American Journal of Public Health. 2002; 92(9): 1518-22. 